\title{
Repeated Electroconvulsive Shock Produces Long-lasting Increases in Messenger RNA Expression of Corticotropin-releasing Hormone and Tyrosine Hydroxylase in Rat Brain \\ Therapeutic Implications
}

\author{
Linda S. Brady, Allison B. Lynn, John R. Glowa, Dung Q. Le, and Miles Herkenham \\ Section on Functional Neuroanatomy, Clinical Neuroendocrinology Branch, National Institute of Mental Health, Bethesda, \\ Maryland 20892
}

\begin{abstract}
Electroconvulsive shock (ECS) is a highly effective therapy for the treatment of major depression, but its mechanisms of action are not known. We report that repeated ECS in rats produces enduring changes in two clinically relevant stress-responsive brain systems: $(a)$ the hypothalamic-pituitary-adrenal axis regulated by corticotropin-releasing hormone (CRH) in the paraventricular nucleus; and $(b)$ the NE system in the locus coeruleus regulated by tyrosine hydroxylase (TH). CRH and TH mRNA levels in these brain regions were assessed by in situ hybridization histochemistry. A single interaural ECS elevated TH but not CRH mRNA measured 24 h later. Repeated daily treatments (3, 7 , or 14) elevated both mRNAs, maximally with 7, correlating with the time course of clinical efficacy. The elevations persisted for 3 (CRH) or 8 wk (TH) after the ECS. No other therapeutic treatment is known to produce such longlasting changes in central nervous system gene expression. The time course of events (delayed onset, long duration) implicate CRH as a principal mediator of the antidepressant effects of ECS. The locus coeruleus-NE system may be important in initiating the central nervous system response. (J. Clin. Invest. 1994. 94:1263-1268.) Key words: corticotropin - melancholic depression - electroconvulsive therapy • hypothalamus $\bullet$ locus coeruleus
\end{abstract}

\section{Introduction}

Electroconvulsive shock (ECS) ${ }^{1}$ is one of the most clinically effective therapies available for the treatment of major depression, and is used primarily in severe cases that do not respond to antidepressant drugs (1-3). The treatment consists of repeated administration of electroconvulsive shock (usually 6-12 treat-

Address correspondence to Linda S. Brady, Section on Functional Neuroanatomy, National Institute of Mental Health, Building 36, Room 2D15, Bethesda, MD 20892.

Received for publication 25 February 1994 and in revised form 19 May 1994.

1. Abbreviations used in this paper: $\mathrm{CRH}$, corticotropin-releasing hormone; ECS, electroconvulsive shock; GR, glucocorticoid receptor; HPA, hypothalamic-pituitary-adrenal; LC, locus coeruleus; MR, mineralocorticoid receptor; POMC, pro-opiomelanocortin; PTZ, pentylenetetrazole; PVN, paraventricular nucleus; $\mathrm{TH}$, tyrosine hydroxylase.

The Journal of Clinical Investigation, Inc. Volume 94, September 1994, 1263-1268 ments, 3 per wk) over a 1-2-wk period, after which the patients show a dramatic improvement that persists for months $(2,3)$. Despite its well-documented therapeutic efficacy, the mechanism(s) of action underlying the antidepressant effects of ECS is not known.

In this study, the effects of acute and repeated ECS treatment in rats are examined to define the persistent central nervous system (CNS) changes that might underlie the therapeutic efficacy of ECS in depression. We have focused on two major CNS systems, namely $(a)$ the hypothalamic-pituitary-adrenal (HPA) axis regulated by the stress-responsive hormone corticotropin-releasing hormone ( $\mathrm{CRH})$ in the hypothalamic paraventricular nucleus (PVN), and (b) the NE system in the locus coeruleus (LC) which is regulated by tyrosine hydroxylase (TH), the rate-limiting enzyme in NE biosynthesis, because they are thought to be dysregulated in major depression in humans (4). Moreover, we have shown that these systems are selectively altered by stress (5) and antidepressant drug treatment $(6,7)$.

\section{Methods}

Animals. Male Sprague-Dawley rats (175-200 g; Taconic Farms Inc., Germantown, NY) were housed three to a cage at $24^{\circ} \mathrm{C}$ with lights on from 0600 to $1800 \mathrm{~h}$. The animal procedures used in these studies were in strict accordance with the National Institutes of Health Guide for the Care and Use of Laboratory Animals and were approved by the National Institute of Mental Health Animal Care and Use Committee.

ECS treatment. ECS was administered to the rats by the application of an 80-mA current via ear-clip electrodes for a duration of $0.5 \mathrm{~s}$ using an ECS device (Annett's Industries, Oxford, United Kingdom). ECStreated rats immediately exhibited generalized tonic-clonic convulsions which lasted 20-30 s. Control animals were treated similarly but received $0 \mathrm{~mA}$ current. Animals were killed $24 \mathrm{~h}$ after the last treatment.

To determine the optimal treatment-effect relationship of ECS on mRNA levels in brain, groups of animals were administered ECS daily for $1,3,7$, or $14 \mathrm{~d}$. After the optimal number of treatments was determined, additional groups of rats were administered ECS in a temporal regimen similar to that used clinically: three times a week (Monday, Wednesday, and Friday) for a total of seven treatments.

To determine the duration of the effects of repeated ECS on mRNA levels in brain, groups of rats were administered ECS daily for $7 \mathrm{~d}$ (the optimal number of treatments determined in the previous study) and were killed 24 h, 3 wk, or 8 wk later.

Pentylenetetrazole treatment. Pentylenetetrazole administration was used as a model of generalized tonic-clonic convulsions to determine if ECS-induced changes in mRNA levels could be reproduced by the induction of generalized seizures or if the effects were specific to ECS treatment. Animals were given pentylenetetrazole $(35 \mathrm{mg} / \mathrm{kg}$, intraperitoneally [i.p.]) or $0.9 \%$ saline $(1 \mathrm{ml} / \mathrm{kg})$ once daily for 1 or $3 \mathrm{~d}$. Pentylenetetrazole produced tonic-clonic seizures in all animals within 1-2 min after injection. Rats were killed $24 \mathrm{~h}$ after the last injection. 
Tissue and plasma collection. Animals were transported singly from the housing room to a treatment room (transport time $<3 \mathrm{~min}$ ) and killed by decapitation between 1000 and $1200 \mathrm{~h}$. Brains were removed, frozen by immersion in 2 -methyl butane at $-30^{\circ} \mathrm{C}$, and stored at $-70^{\circ} \mathrm{C}$ before sectioning. Adrenal glands were removed, dissected on ice, and weighed. Trunk blood was collected on ice in tubes containing EDTA, centrifuged $\left(3,000 \mathrm{rpm}\right.$ for $20 \mathrm{~min}$ at $\left.4^{\circ} \mathrm{C}\right)$, and the plasma was frozen at $-70^{\circ} \mathrm{C}$. Plasma $\mathrm{ACTH}$ and corticosterone levels were measured by RIA kits (ICN Biochemicals, Cleveland, $\mathrm{OH}$ ). The interassay coefficient of variance was $<10 \%$.

In situ hybridization histochemistry. Frozen sections ( $15 \mu \mathrm{m}$ thick) were cut coronally through the midportion of the parvocellular region of the PVN ( $-1.8 \mathrm{~mm}$ relative to bregma), dorsal hippocampus $(-3.3$ $\mathrm{mm}$ relative to bregma), pituitary, and $\mathrm{LC}$ ( $-9.7 \mathrm{~mm}$ relative to bregma) (8). Sections were thaw-mounted onto gelatin-coated slides, dried, and stored at $-40^{\circ} \mathrm{C}$ before processing for in situ hybridization histochemistry.

Synthetic 48-base oligodeoxyribonucleotide probes were directed against CRH bases 496-543 (9), TH bases 1441-1488 (10), and proopiomelanocortin (POMC) bases encoding amino acids 96-111 (11). The probes were labeled at the 3 '-end using $\left[\alpha-{ }^{35}\right.$ S $]$ dATP (sp act $>1,000 \mathrm{Ci} / \mathrm{mmol}$; New England Nuclear, Boston, MA), terminal deoxynucleotidyl transferase ( $25 \mathrm{U} / \mu \mathrm{l}$; Boehringer Mannheim Corp., Indianapolis, IN), and tailing buffer (Bethesda Research Laboratory, Bethesda, MD).

Ribonucleotide probes were directed against bases 81-528 of the rat glucocorticoid receptor (GR) (12) and 513 bases encoding the carboxyterminal 25 amino acids and a portion of the $3^{\prime}$-untranslated region of the rat mineralocorticoid receptor (MR) (13). Antisense probes were transcribed using $\left[\alpha-{ }^{35} \mathrm{~S}\right] \mathrm{UTP}$ (sp act 1,000-1,500 Ci/mmol; New England Nuclear) and the Riboprobe System (Promega Corp., Madison, WI).

The in situ hybridization protocols were performed as described previously $(6,7)$. Slides and ${ }^{14} \mathrm{C}$-standards (American Radiolabeled Chemicals, St. Louis, MO) of known radioactivity were placed in $\mathrm{x}$ ray cassettes, apposed to film (Hyperfilm- $\beta$ Max; Amersham Corp., Arlington Heights, IL) for 2 h-7 d, and developed (D19; Eastman Kodak Co., Rochester, NY) for $5 \mathrm{~min}$ at $20^{\circ} \mathrm{C}$.

Data analysis. Autoradiographic film images of brain sections and ${ }^{14} \mathrm{C}$-standards were digitized on a Macintosh II computer-based image analysis system with IMAGE software (Wayne Rasband, Research Services Branch, National Institute of Mental Health). Light transmittance through the film at PVN, LC, and pituitary levels was measured by outlining the structure with the mouse cursor. A density slice function was applied to each hippocampal section to select and measure transmittance confined to the cellular layers of the CA fields and dentate gyrus. A calibration curve was constructed using the transmittance values of the ${ }^{14} \mathrm{C}$-standards. Transmittance measurements for each probe were made on four consecutive sections from each brain region per rat and were converted to disintegrations per minute per milligram of wet weight of tissue using the calibration curve.

The average value for each animal in experimental or control groups (based on four sections per animal) was used to calculate group means ( $n=6-8$ per group). The relative amount of probe hybridized in each brain region of the ECS-treated animals was expressed as a percentage of the control group \pm SEM.

Statistical significance between brain regions in control and experimental groups was determined by two-way ANOVA using SuperANOVA software (Abacus Concepts, Berkeley, CA). The Bonferroni/Dunn (control) test was used for post-hoc comparisons of the ECS treatment groups with the sham-treated control groups at each time point. A $P$ value of 0.05 was chosen as the level of statistical significance.

\section{Results}

Optimal number of ECS treatments on mRNA levels in brain. A single ECS treatment produced selective alterations in mRNA

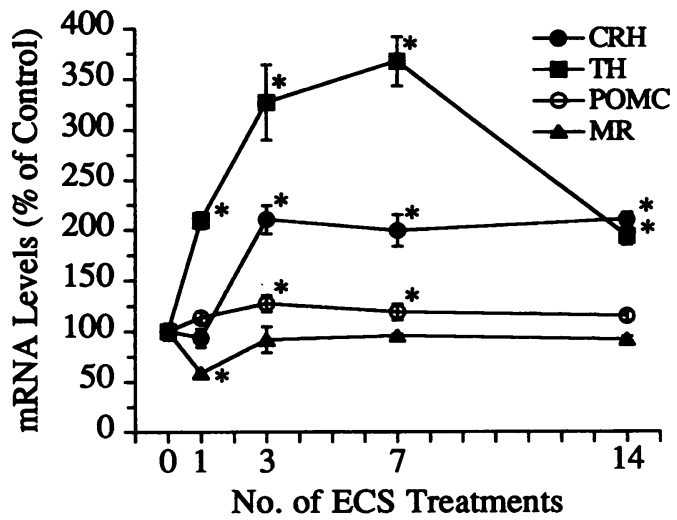

Figure 1. Treatment-dependent effects of ECS on mRNA levels in rat brain. In situ hybridization histochemistry was used to assess the effects of $1,3,7$, or 14 ECS treatments on mRNA levels of CRH in the hypothalamic PVN, POMC in the anterior pituitary, MR in the hippocampus, and TH in the LC. Levels of mRNA were quantitated by densitometric analysis of film autoradiographs. Values are the mean and SEM ( $n=6-8$ ) determined $24 \mathrm{~h}$ after the last ECS treatment. Seven ECS treatments produced maximal effects on CRH and TH mRNA levels. ${ }^{*} P<0.01$ relative to control.

levels in brain $24 \mathrm{~h}$ after its administration. The largest effect of acute ECS was a marked twofold elevation in TH mRNA levels in the LC (Fig. 1). In the hippocampus, acute ECS reduced MR mRNA levels by $41 \%$. In the hippocampal subfields, MR message levels were reduced by $57 \%$ in CA2 and dentate gyrus, by $44 \%$ in CA1, and by $29 \%$ in CA3-4. GR mRNA levels were unchanged in the hippocampus, PVN, and anterior pituitary. CRH mRNA levels in the PVN and POMC mRNA levels in the anterior pituitary were not changed after a single ECS treatment. Plasma ACTH levels were elevated 2.5-fold by acute ECS but plasma corticosterone levels and adrenal gland weight were unchanged (Table I).

Repeated ECS $(3,7$, or 14 daily treatments) produced large elevations in mRNA levels of peptides and biosynthetic enzymes in brain $24 \mathrm{~h}$ after the end of treatment. TH mRNA levels in the LC were markedly increased by ECS with a peak effect seen after seven treatments (367\% of control) (Fig. 1). CRH mRNA levels in the PVN rose to their peak after three treatments (210\% of control) and then plateaued (Fig. 1). POMC mRNA levels in the anterior pituitary were significantly increased after 3 and 7 ECS treatments (19-27\% increase, $P$ $<0.05$ ) and no longer differed from control levels by 14 treatments. MR mRNA levels in the hippocampus were not altered by repeated ECS treatment.

Repeated daily ECS administration elevated plasma ACTH and corticosterone levels, reaching peak effects, a 27-fold increase in ACTH and a 3-fold increase in corticosterone, after 7 treatments (Table I). At this time point, adrenal gland weight was increased by $81 \%$, and body weight was reduced by $13 \%$ (Table I). After 14 ECS treatments, elevations in ACTH and corticosterone levels were smaller in magnitude, and no effect was seen on adrenal gland weight. Body weight, however, continued to be reduced by $15 \%$ at this time point (Table I).

Effects induced by seven ECS treatments administered three times per week. After the optimal number of ECS treatments was determined to be seven, ECS was administered three times per week for a total of seven treatments in order to mimic the 
Table I. Effects of ECS Treatment or Pentylenetetrazol Administration on Plasma ACTH and Corticosterone, Adrenal Gland Weight, and Body Weight

\begin{tabular}{|c|c|c|c|c|c|c|c|c|}
\hline \multirow[b]{2}{*}{ No. of treatments } & \multicolumn{2}{|c|}{ ACTH } & \multicolumn{2}{|c|}{ Corticosterone } & \multicolumn{2}{|c|}{ Adrenal gland weight } & \multicolumn{2}{|c|}{ Body weight } \\
\hline & Sham & Treated & Sham & Treated & Sham & Treated & Sham & Treated \\
\hline & \multicolumn{2}{|c|}{$p g / m l$} & \multicolumn{2}{|c|}{$n g / m l$} & \multicolumn{2}{|c|}{$m g$} & \multicolumn{2}{|c|}{$g$} \\
\hline \multicolumn{9}{|l|}{ ECS } \\
\hline 1 & $32 \pm 15$ & $83 \pm 40^{*}$ & $149 \pm 40$ & $170 \pm 48$ & & & $270 \pm 13$ & $268 \pm 3$ \\
\hline 3 & $29 \pm 13$ & $115 \pm 55^{*}$ & $142 \pm 16$ & $162 \pm 55$ & $17.6 \pm 0.7$ & $19.7 \pm 1.2$ & $270 \pm 7$ & $263 \pm 4$ \\
\hline 7 & $22 \pm 9$ & $596 \pm 88^{*}$ & $107 \pm 20$ & $342 \pm 79 *$ & $16.4 \pm 1.2$ & $29.7 \pm 1.4^{*}$ & $268 \pm 10$ & $233 \pm 10^{*}$ \\
\hline 14 & $37 \pm 5$ & $300 \pm 110^{*}$ & $138 \pm 6$ & $265 \pm 28 *$ & $19.0 \pm 1.1$ & $22.1 \pm 0.8$ & $330 \pm 10$ & $267 \pm 5^{*}$ \\
\hline 7 (3 per week) & $40 \pm 16$ & $452 \pm 77^{*}$ & $127 \pm 35$ & $165 \pm 39$ & $20.4 \pm 2.2$ & $22.3 \pm 0.9$ & $335 \pm 9$ & $284 \pm 9 *$ \\
\hline \multicolumn{9}{|l|}{ Pentylenetetrazol } \\
\hline 1 & $30 \pm 12$ & $908 \pm 64^{*}$ & $135 \pm 15$ & $354 \pm 22 *$ & & & & \\
\hline 3 & $34 \pm 16$ & $448 \pm 179 *$ & $145 \pm 40$ & $283 \pm 27 *$ & & & & \\
\hline
\end{tabular}

Values are given as mean $\pm \operatorname{SEM}(n=6-8) . \quad{ }^{*} P<0.05$ relative to control.

temporal spacing of ECS treatments used clinically. With this regimen, repeated ECS produced smaller increases in mRNA levels of TH in the LC (157 $\pm 4 \%$ of control) and CRH in the PVN (158 $\pm 17 \%$ of control) than after seven daily treatments (Table I, Fig. 1). No increase in POMC mRNA levels was seen in the anterior pituitary (Table I). Plasma ACTH levels were elevated to the same extent as after seven daily ECS treatments, whereas plasma corticosterone levels and adrenal gland weight did not differ from control (Table I). Body weight was reduced by $20 \%$ with this ECS regimen (Table I).

Persistence of the effects induced by seven daily ECS treatments. Because seven daily ECS treatments produced a peak increase in TH mRNA levels in the LC and CRH mRNA levels in the PVN, this number of treatments was chosen to examine the persistence of ECS-induced changes in mRNA levels in brain. 3 wk after discontinuation of ECS, TH mRNA levels in the LC continued to be elevated, but to a lesser degree ( $133 \pm 8 \%$ of control), (Figs. 2 and 3,c and $d$ ). 8 wk after ECS treatment,

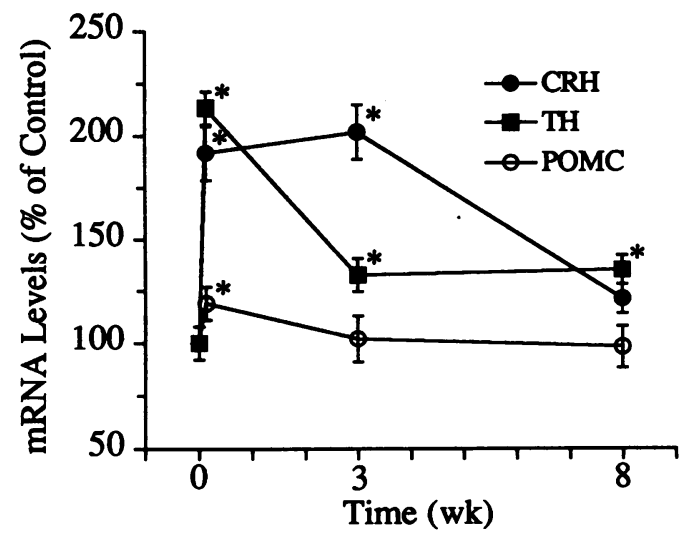

Figure 2. Persistent effects of seven ECS treatments on mRNA expression in brain. In situ hybridization histochemistry was used to assess the effects of ECS on mRNA levels. mRNA levels were quantitated by densitometric analysis of film images. Values are the mean and SEM $(n=6-8)$. The zero time point data were determined $24 \mathrm{~h}$ after ECS treatment. The mean and SEM of the control groups was $100 \pm 6$. Repeated ECS produced long-lasting increases in mRNA levels of CRH in the PVN and TH in the LC. $* P<0.01$ relative to control. the increased TH mRNA levels in the LC persisted with no further decrement.

CRH mRNA levels in the PVN were elevated without a decrement in effect $(202 \pm 13 \%$ of control $) 3 \mathrm{wk}$ after discontinuation of ECS (Figs. 2 and $4 \mathrm{c}$ ). The increase in CRH message was no longer evident after 8 wk (Figs. 2 and $4 c$ ).

No alterations in POMC mRNA levels in the anterior pituitary or in plasma levels of ACTH and corticosterone were evident 3 wk after repeated ECS treatment. Adrenal gland weight and body weight did not differ from control 3 wk after ECS treatment.

Effects of pentylenetetrazole-induced seizures on brain $m R N A$. Pentylenetetrazole (PTZ) administration was used as a model of generalized tonic-clonic convulsions to determine if ECS-induced changes in mRNA levels could be reproduced by the induction of generalized seizures or if the effects were specific to ECS treatment. Acute administration of PTZ (35 mg/ $\mathrm{kg}$, i.p.) produced tonic-clonic seizures in all animals. These seizures were longer in duration than those induced by ECS. PTZ increased CRH mRNA levels in the PVN (159 $\pm 9 \%$ of control, $P<0.05)$ and elevated plasma levels of ACTH and corticosterone $24 \mathrm{~h}$ after treatment (Table I). Repeated PTZ administration for $3 \mathrm{~d}$ elevated plasma levels of ACTH and corticosterone (Table I), but did not significantly alter CRH mRNA levels in the PVN $24 \mathrm{~h}$ after the last injection.

\section{Discussion}

A single exposure to ECS increased TH mRNA levels in the LC and decreased MR mRNA levels in the hippocampal CA fields and dentate gyrus. These changes were accompanied by an increase in plasma levels of ACTH. The effects were measured $24 \mathrm{~h}$ after ECS and thus reflect the profile of CNS changes induced by the ECS treatment rather than the immediate effects produced by the seizure itself.

The increase in TH mRNA levels in the LC after a single ECS may be an adaptive compensatory response to the ECSinduced increase in utilization of NE in terminal regions in brain. As a consequence of a single ECS, NE synthesis is stimulated in the LC and its terminal fields (14) and a rapid, shortlasting increase in TH enzyme activity is induced $(15,16)$. The 

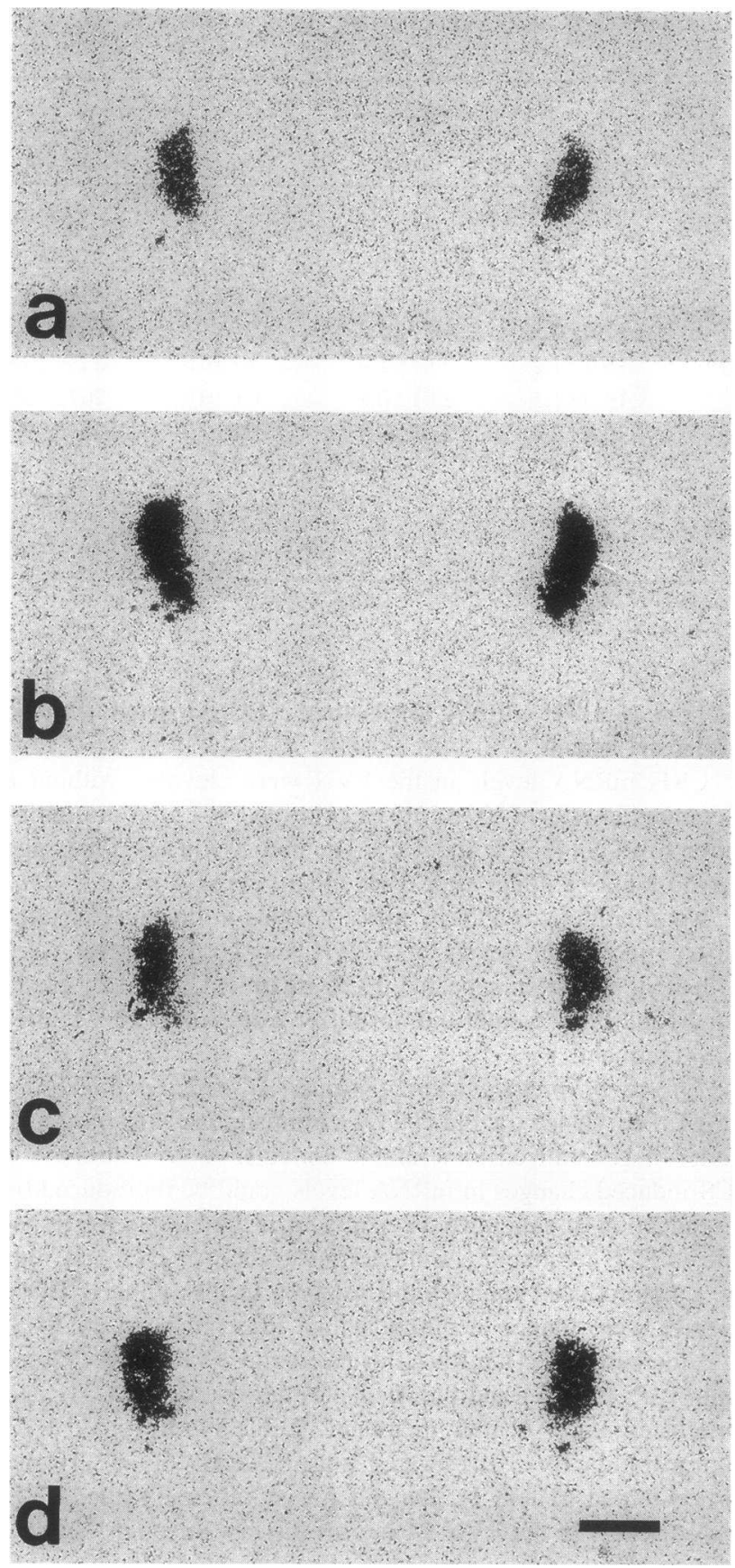

Figure 3. Persistent effects of repeated ECS on the LC-NE system. Film autoradiographic images of TH mRNA in the LC of control $(a)$ and ECS-treated animals $(b-d)$ at $24 \mathrm{~h}(b), 3 \mathrm{wk}(c)$, and $8 \mathrm{wk}(d)$ after discontinuation of 7 daily ECS treatments. TH mRNA levels in the LC continued to be significantly elevated $8 \mathrm{wk}$ after repeated ECS treatment. Bar $=500 \mu \mathrm{m}$.

increase in TH mRNA levels, a twofold increase in the LC measured $24 \mathrm{~h}$ after ECS, is much larger in magnitude and longer in duration than that produced by acute stress $(5,17,18)$ or reserpine administration (19), treatments which stimulate NE turnover.

An immediate and transient increase in corticosterone levels has been reported previously 10-30 min after a single ECS,
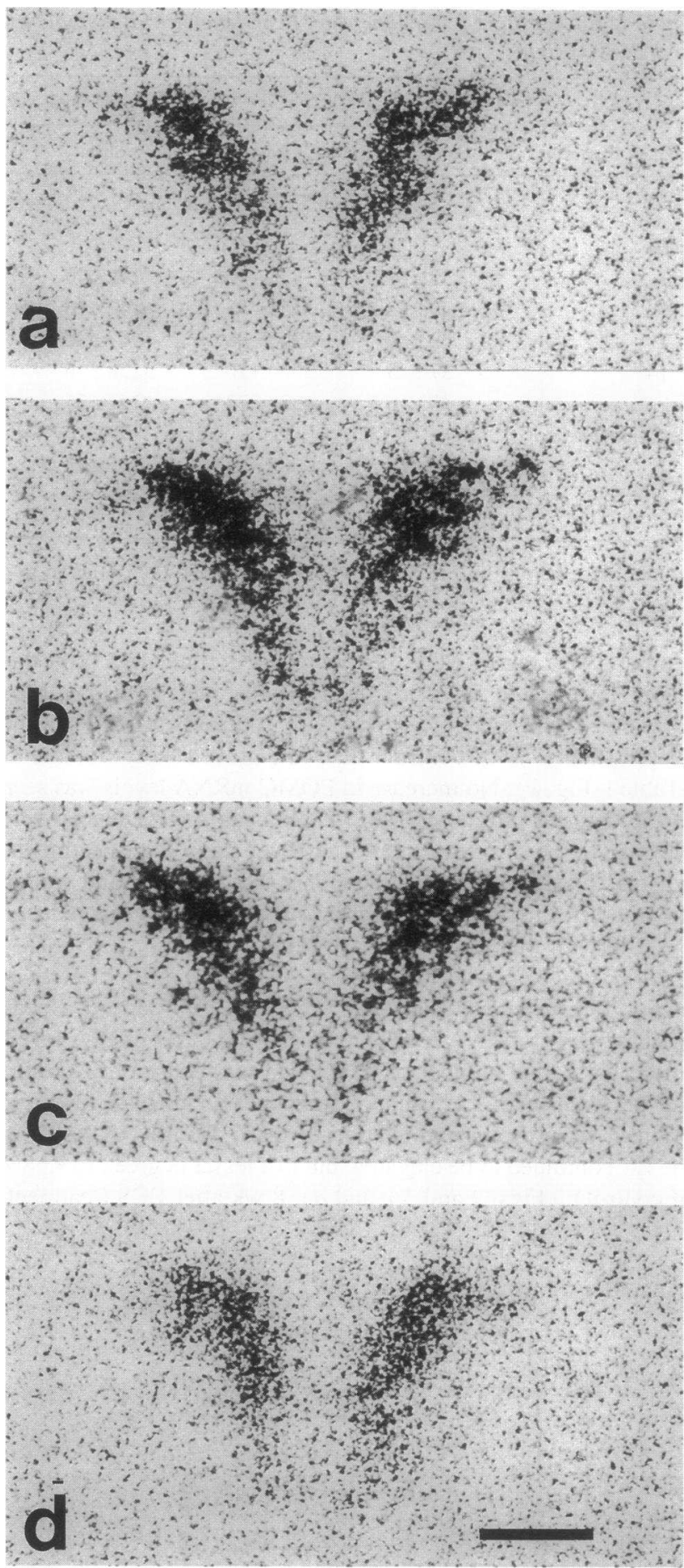

Figure 4. Persistent effects of repeated ECS on the hypothalamic CRH system. Film autoradiographic images of CRH mRNA in the PVN of control $(a)$ and ECS-treated rats $(b-d)$ at $24 \mathrm{~h}(b), 3 \mathrm{wk}(c)$, and 8 wk $(d)$ after discontinuation of 7 daily ECS treatments. Note the pronounced and enduring increase in CRH mRNA levels in the parvocellular PVN 3 wk after repeated ECS treatment. Bar $=200 \mu \mathrm{m}$.

followed by a return to baseline by $1 \mathrm{~h}(20)$. The temporary decrease in hippocampal MR mRNA levels seen $24 \mathrm{~h}$ after a single ECS may be an acute compensatory response to eleva- 
tions in corticosterone which may serve to reduce negative feedback onto the PVN (21).

Plasma levels of ACTH were elevated $24 \mathrm{~h}$ after one, three, or seven (three times per week) ECS treatments, whereas corticosterone levels were unaltered. The dissociation in plasma measures could be the result of transporting animals from the housing room to the treatment room (transport time $<3 \mathrm{~min}$ ) before killing, if the stress of ECS treatment $24 \mathrm{~h}$ earlier resulted in facilitation of ACTH release in the treated rats.

Elevations in mRNA levels of stress-responsive elements in the hypothalamic and pituitary components of the HPA axis, CRH in the PVN and POMC in the anterior pituitary, were not evident after a single ECS. Instead, multiple ECS treatments were required to increase these message levels. Maximal activation of the HPA axis (peak increases in PVN CRH mRNA levels, plasma ACTH and corticosterone levels, and adrenal gland weight) and maximal activation of the LC-NE system were seen after seven daily ECS treatments. Additional treatment for $14 \mathrm{~d}$ did not further increase mRNA levels.

Multiple ECS treatments did not alter the mRNA levels of MR or GR in the hippocampus despite the presence of large and persistent elevations in plasma ACTH and corticosterone. We have shown previously that hippocampal MR message is altered after acute but not chronic stress (5). The hippocampus may be more sensitive to acute episodic variations in corticosterone than it is to chronically elevated levels.

To reproduce the temporal regimen of ECS treatments used clinically, ECS was administered three times per week for a total of seven treatments. The effects of this treatment were qualitatively similar to those produced by seven consecutive ECS administrations. However, the ECS-induced increases in mRNA levels of TH in the LC and CRH in the PVN were less in magnitude, and no adrenal gland hypertrophy or loss of body weight was apparent. Thus, the frequency (temporal spacing) of ECS treatments is important in determining the degree of activation of the HPA axis and LC-NE system.

It is not unexpected that ECS treatment altered the activity of the hypothalamic CRH and LC-NE systems, since these systems are key components of the CNS regulatory mechanisms responding to stress (18). The effects of repeated ECS on mRNA levels of TH in the LC and CRH in the PVN are greater in magnitude and duration than the effects of repeated stress on these messages $(5,17,22)$, suggesting that in rats ECS may be the most potent available stressor.

To elucidate the neurochemical mechanisms responsible for the therapeutic effects of ECS, or of any antidepressant agent, it is important to establish that $(a)$ the therapeutic effects appear only after multiple treatments, and $(b)$ that these effects persist for an extended period of time after the termination of treatment. In this study, we have identified two CNS systems, hypothalamic CRH and the LC-NE system, that satisfy these criteria. The evidence is as follows. First, CRH mRNA levels in the PVN are increased after repeated ECS treatments but not after a single ECS. Second, hypothalamic CRH and the LC-NE system are maximally activated after repeated daily ECS treatments. Third, the number of treatments producing maximal activation of the HPA axis and LC-NE system (seven) lies within the range of therapeutic efficacy of ECS in treating depression $(1-3,16)$. These two systems are also activated when ECS treatment is administered three times per week in a temporal regimen similar to that used clinically. Finally, repeated ECS treatments produce marked and enduring elevations in mRNA levels of CRH in the PVN ( 3 wk) and TH in the LC (8 wk) (Fig. 2). The therapeutic effects of ECS dissipate within 23 mo after ECS treatment, and maintenance electroconvulsive therapy or antidepressant drug administration must be initiated within this time period to prevent a relapse of depression (1$3,16,23,24)$. Collectively, the temporal aspects of the CRH effect in this study indicate that hypothalamic CRH plays a key role in the antidepressant effects of ECS. The immediate and prolonged activation of the LC-NE system by ECS may be important in initiating and maintaining the response of hypothalamic CRH to ECS.

We reported previously that repeated administration of antidepressant drugs decreases mRNA levels of CRH in the PVN $(6,7)$. We suggested that the $\mathrm{CRH}$ effect is relevant to the therapeutic efficacy of antidepressant drugs in depression because $(a)$ the temporal aspects of the effect agree with the delayed onset of therapeutic efficacy, and $(b)$ the direction of the effect is opposite and may therefore counteract the hypersecretion of CRH found in major depression $(4,25-29)$.

In this study, we show that ECS treatment differs from that of antidepressant drugs by increasing rather than decreasing levels of CRH mRNA. Further studies of the effects of ECS treatment on mRNA levels in stressed animals or in animal models of depression will reveal more about the mechanism of action of ECS and the role of hypothalamic CRH. At this point in our studies, the increases in PVN CRH message and LC TH message by ECS suggest that elevated levels per se of CRH and NE observed in depression and in animal models of chronic stress are not causal factors for these conditions.

Two hypotheses of the antidepressant efficacy of ECS have been proposed. The receptor hypothesis emphasizes alterations in neurotransmitter receptors as the primary mechanism of action of ECS in affective disorders (30-33). This hypothesis invokes common mechanisms in mediating the therapeutic effects of ECS and antidepressant drugs but does not account for the finding that some depressed patients respond to ECS but not to drugs (34). The neuropeptide hypothesis suggests that dysregulation of hypothalamic peptides underlies the pathogenesis of affective disorders $(4,25,35-37)$. In depressed patients who respond to a course of ECS treatment, ECS alters neuroendocrine secretion of $\mathrm{CRH}, \beta$-endorphin, growth hormone, prolactin, and somatostatin $(36,38-41)$. Our findings suggest a merger of the two hypotheses: the antidepressant effects of ECS are mediated by an initial activation of neurotransmitter systems including the LC-NE system followed by a delayed activation of hypothalamic neuropeptide systems, primarily CRH.

In summary, repeated ECS produces marked and enduring elevations in mRNA levels of TH in the LC and CRH in the PVN. No other therapeutic drug or treatment is known to produce such persistent changes in CNS gene expression. We suggest that the ability of ECS to resolve depressions which are not responsive to antidepressant drug treatment may be related to its unique ability to produce a long-lasting activation of the hypothalamic CRH and LC-NE systems.

\section{Acknowledgments}

Dr. Philip W. Gold (Chief, Clinical Neuroendocrinology Branch, National Institute of Mental Health) gave advice and encouragement and Dr. Susan R. Weiss (Biological Psychiatry Branch, National Institute of Mental Health) provided the ECS device. 


\section{References}

1. Enns, M. 1991. Electrical dosage and efficacy in electroconvulsive therapy. Can. J. Psychiatry. 36:344-348.

2. Pearlman, C. 1991. Electroconvulsive therapy: current concepts. Gen. Hosp. Psychiatry 13:128-137.

3. Reid, W. 1993. Electroconvulsive therapy. Tex. Med. 89:58-62.

4. Gold, P. W., F. K. Goodwin, and G. P. Chrousos. 1988. Clinical and biochemical manifestations of depression. Relation to neurobiology of stress. $N$. Engl. J. Med. 319:348-353 and 413-420.

5. Mamalaki, E., R. Kvetnansky, L. S. Brady, P. W. Gold, and M. Herkenham. 1992. Repeated immobilization stress alters tyrosine hydroxylase, corticotropinreleasing hormone and corticosteroid receptor messenger ribonucleic acid levels in rat brain. J. Neuroendocrinol. 4:689-699.

6. Brady, L. S., H. J. Whitfield, Jr., R. J. Fox, P. W. Gold, and M. Herkenham. 1991. Long-term antidepressant administration alters corticotropin-releasing hormone, tyrosine hydroxylase, and mineralocorticoid receptor gene expression in rat brain. Therapeutic implications. J. Clin. Invest. 87:831-837.

7. Brady, L. S., P. Gold, M. Herkenham, A. Lynn, and H. J. Whitfield, Jr. 1992. The antidepressants fluoxetine, idazoxan, and phenelzine alter corticotropinreleasing hormone and tyrosine hydroxylase mRNA levels in rat brain: therapeutic implications. Brain Res. 572:117-125.

8. Paxinos, G., and C. Watson. 1986. In The Rat Brain in Stereotaxic Coordinates. Academic Press Inc., Orlando, FL.

9. Jingami, H., N. Mizuno, H. Takahashi, S. Shibahara, Y. Furutani, H. Imura, and S. Numa. 1985. Cloning and sequence analysis of cDNA for rat corticotropinreleasing factor precursor. FEBS (Fed. Eur. Biochem. Soc.) Lett. 191:63-66.

10. Grima, B., A. Lamouroux, F. Blanot, N. F. Biquet, and J. Mallet. 1985. Complete coding sequence of rat tyrosine hydroxylase mRNA. Proc. Natl. Acad. Sci. USA. 82:617-621.

1. Drouin, J., M. Chamberland, J. Charron, L. Jeannotte, and M. Nemer. 1985. Structure of the rat pro-opiomelanocortin (POMC) gene. FEBS (Fed. Eur. Biochem. Soc.) Lett. 193:54-58.

12. Miesfeld, R., S. Rusconi, P. J. Godowski, B. A. Maler, S. Okret, A. C Wikström, J.-Å. Gustafsson, and K. R. Yamamoto. 1986. Genetic complementation of a glucocorticoid receptor deficiency by expression of cloned receptor cDNA. Cell. 46:389-399.

13. Arriza, J. L., R. B. Simerly, L. W. Swanson, and R. M. Evans. 1988. The neuronal mineralocorticoid receptor as a mediator of glucocorticoid response. Neuron. 1:887-900.

14. Glue, P., M. Costello, A. Pert, A. Mele, and D. Nutt. 1990. Regional neurotransmitter responses after acute and chronic electroconvulsive shock. Psychopharmacology. 100:60-65.

15. Masserano, J., G. Takimoto, and N. Weiner. 1981. Electroconvulsive shock increases tyrosine hydroxylase activity in brain and adrenal gland of rat. Science (Wash. DC). 214:662-665.

16. Weiner, N., M. Hossain, and J. Masserano. 1991. The effects of electroconvulsive shock on catecholamine function in the locus coeruleus and hippocampus. J. Neural Transm. 34:3-9.

17. Smith, M., L. S. Brady, J. Glowa, P. W. Gold, and M. Herkenham. 1991. Effects of stress and adrenalectomy on tyrosine hydroxylase mRNA levels in the locus coeruleus by in situ hybridization. Brain Res. 544:26-32.

18. Brady, L. S. 1994. Stress, antidepressant drugs, and the locus coeruleus. Brain Res. Bull. In press.

19. Faucon Biguet, N., M. Buda, A. Lamouroux, D. Samolyk, and J. Mallet. 1986. Time course of the changes of TH mRNA in rat brain and adrenal medulla after a single injection of reserpine. EMBO (Eur. Mol. Biol. Organ.) J. 5:287291.

20. Thiagarajan, A., C. Gleiter, I. Mefford, R. Eskay, and D. Nutt. 1989. Effect of a single and repeated electroconvulsive shock on the hypothalamic pituitary-adrenal axis and plasma catecholamines in rats. Psychopharmacology. 97:548-552.

21. Herman, J., W. Cullinan, E. Young, H. Akil, and S. Watson. 1992. Selective forebrain fiber tract lesions implicate ventral hippocampal structures in tonic regulation of paraventricular nucleus corticotropin-releasing hormone (CRH) and arginine vasopressin (AVP) mRNA expression. Brain Res. 592:228-238.
22. Herman, J., M. K.-H. Schafer, C. Sladek, R. Day, E. Young, H. Akil, and S. Watson. 1989. Chronic electroconvulsive shock treatment elicits up-regulation of CRF and AVP mRNA in select populations of neuroendocrine neurons. Brain Res. 501:235-246.

23. Monroe, R. 1991. Maintenance electroconvulsive therapy. Psychiatr. Clin. North Am. 14:947-960.

24. Sackeim, H. A., J. Prudic, D. Devanand, J. Kiersky, L. Fitzsimons, B. Moody, M. McElhiney, E. Coleman, and J. Settembrino. 1993. Effects of stimulus intensity and electrode placement on the efficacy and cognitive effects of electroconvulsive therapy. $N$. Engl. J. Med. 328:839-846.

25. Gold, P. W., G. Chrousos, C. Kellner, R. Post, A. Roy, P. Avgerinos, H. Schulte, E. Oldfield, and D. Loriaux. 1984. Psychiatric implications of basic and clinical studies with corticotropin-releasing factor. Am. J. Psychiatry. 141:619627.

26. Nemeroff, C. B., E. Widerlöv, G. Bissette, H. Walléus, I. Karlsson, K Eklund, C. D. Kilts, P. T. Loosen, and W. Vale. 1984. Elevated concentrations of CSF corticotropin-releasing factor-like immunoreactivity in depressed patients. Science (Wash DC) 226:1342-1343.

27. Gold, P. W., D. L. Loriaux, A. Roy, M. A. Kling, J. R. Calabrese, C. H. Kellner, L. K. Nieman, R. M. Post, D. Pickar, W. Gallucci, et al. 1986. Responses to corticotropin-releasing hormone in the hypercortisolism of depression and Cushing's disease. Pathological and diagnostic implications. N. Engl. J. Med. 314:1329-1335.

28. Roy, A., D. Pickar, S. Paul, A. Doran, G. P. Chrousos, and P. W. Gold 1987. CSF corticotropin-releasing hormone in depressed patients and normal control subjects. Am. J. Psychiatry. 144:641-645.

29. Kling, M. A., A. Roy, A. R. Doran, J. R. Calabrese, D. R. Rubinow, H. J. Whitfield, Jr., C. May, R. M. Post, G. P. Chrousos, and P. W. Gold. 1991 Cerebrospinal fluid immunoreactive corticotropin-releasing hormone and adrenocorticotropin secretion in Cushing's disease and major depression: potential clinical implications. J. Clin. Endocrinol. \& Metab. 72:260-271.

30. Bunney, W., Jr., R. Post, A. Anderson, and R. Kopanda. 1977. A neuronal receptor sensitivity mechanism in affective illness (a review of evidence). Psychopharmacol Commun. 1:393-405.

31. Grahame-Smith, D. A. Green, and D. Costain. 1978. Mechanism of the antidepressant action of electroconvulsive therapy. Lancet. i:254-256.

32. Lehrer, B. 1984. Electroconvulsive shock and neurotransmitter receptors: implications for the mechanism of action and adverse effects of electroconvulsive therapy. Biol. Psychiatry. 19:361-383.

33. Gleiter, C., and D. Nutt. 1989. Chronic electroconvulsive shock and neurotransmitter receptors - an update. Life Sci. 44:985-1006.

34. Kendell, R. 1981. The present status of electroconvulsive therapy. Br. J. Psychiatry. 139:265-283.

35. Fink, M., and J. Ottoson. 1980. A theory of convulsive therapy in endogenous depression: significance of hypothalamic functions. Psychiatry Res. 2: 49-61.

36. Nemeroff, C., G. Bissette, H. Akil, and M. Fink. 1991. Neuropeptide concentrations in the cerebrospinal fluid of depressed patients treated with electroconvulsive therapy. Corticotropin-releasing factor, $\beta$-endorphin and somatostatin. Br. J. Psychiatry. 158:59-63.

37. Chrousos, G., and P. Gold. 1992. The concepts of stress and stress system disorders. JAMA (J. Am. Med. Assoc.). 267:1244-1252.

38. Delitalia, G., A. Masal, G. Rosati, I. Aiello, and V. Agnetti. 1977. Effect of electroconvulsive therapy (electroshock) on plasma ACTH, GH, LH, FSH, TSH and LL-OH-CS in patients with mental disorders. Parminerva Med. 19:237243.

39. Deakin, J., I. Ferrier, T. Crow, E. Johnstone, and P. Lawler. 1983. Effects of ECT on pituitary hormone release: relationship to seizure, clinical variables and outcome. Br. J. Psychiatry. 143:618-624.

40. Weizman, A., I. Gil-Ad, D. Grupper, S. Tyano, and Z. Laron. 1987. The effect of acute and repeated electroconvulsive treatment on plasma $\beta$-endorphin, growth hormone, prolactin and cortisol secretion in depressed patients. Psychopharmacology. 93:122-126.

41. Rudorfer, M., E. Risby, O. Osman, P. Gold, and W. Potter. 1991. Hypothalamic-pituitary-adrenal axis and monoamine transmitter activity in depression: a pilot study of central and peripheral effects of electroconvulsive therapy. Biol. Psychiatry. 29:253-264. 